\title{
The Creative Process, Memoir, And Redemption
}

Lawrence Karn, Otsuma Women's University, Japan

Takahiko Hattori, Otsuma Women's University, Japan

\begin{abstract}
Stories live to be told to others, Dan McAdams (2008) writes:

Life stories therefore are continually made and remade in social relationships and in the overall social context provided by culture. As psychosocial constructions, life stories reflect the values, norms, and power differentials inherent in societies, wherein they have their constitutive meanings. The construction of coherent life stories is an especially challenging problem for adults living in contemporary modern (and postmodern) societies, wherein selves are viewed as reflexive projects imbued with complexity and depth, ever changing yet demanding a coherent framing.
\end{abstract}

This paper considers the memoir as a kind of life story, to be explored through selected memoirists, researchers, and scholars by focusing on the relationship between identity construction, memory, history, and imagination. Narrative structure, as well as the compelling experiences and ideas detailed in memoirs, will be analyzed to arrive at a better understanding of issues related to the creative process.

Keywords: Studies in Language and Culture; Narrative Identity; Memoir, Life Stories; Creative Process; Social Context

\section{INTRODUCTION}

$\mathrm{n}$ the heated exchange of differences of opinion, the plea let me tell you my side of the story is a redemption-seeking gesture. Storytelling in the form of personal memoir is like telling one's side of the story in a way that both creates and reflects one's life context. The notion of redemption, inspired by Dan McAdams' (2008) concept of the redemptive self, will be used as an element of commonality in works of some memoirists, scholars, and researchers in the exploration of the relationship between identity construction, memory, history, and imagination. These will be explored using, as a framing device, six principles of personal narratives and life stories that McAdams (2008) discusses. Our purpose is to exhibit how narrative structure, as well as compelling experiences and ideas detailed in memoirs, may lead to an understanding of issues related to the creative process.

While the taxonomy we begin with comes from McAdams (2008) article, "Personal Narratives and the Life Story," his concept of the redemptive self is stated succinctly elsewhere in the following extract.

Here is a personal story - a biographical script of sorts - that many very productive and caring American adults see as their own: In the beginning, I learn that I am blessed, even as others suffer. When I am still very young, I come to believe in a set of simple core values to guide me through a dangerous life terrain. As I move forward in life, many bad things come my way — sin, sickness, abuse, addiction, injustice, poverty, stagnation. But bad things often lead to good outcomes-my suffering is redeemed. Redemption comes to me in the form of atonement, recovery, emancipation, enlightenment, upward social mobility, and/or the actualization of my good inner self. As the plot unfolds, I continue to grow and progress. I bear fruit; I give back; I offer a unique contribution. I will make a happy ending, even in a threatening world.

I call this story the redemptive self. ${ }^{1}$ 
In considering memoir as a species of life story, redemptive elements will serve as a motif. The six principles from McAdams' (2008) "Personal Narratives and the Life Story" are the canvas on which four considerations -identity construction, memory, history, and imagination - is presented.

\section{Setting Out the Two-Part Approach}

At the onset, it will be useful to set out McAdams's (2008) principles with some discussion; this is the substance of Part One: Life Stories as Psychosocial Creations.

In Part Two: Analysis of Selected Memoirists, in-depth analysis of a selection of memoirists will be presented. The following perspectives are brought into play: the interaction of identity construction, memory, history, and imagination are examined; memoirists' techniques - their use of narrative structures and use of language to communicate their experiences and ideas - will be analyzed for insights into the creative process. Throughout, considerations from scholars and researchers will be added.

\section{Part One: Life Stories as Psychosocial Creations}

Dan McAdams (2008) says that in "the best research being done in personality psychology today on personal narratives and the life story ... a key concept in much of this work is narrative identity [McAdams' 2008 italics], which refers to an individual's internalized, evolving and integrative story of the self" (McAdams 2008, p. 242). ${ }^{2} \mathrm{He}$ declares, "The self comes to terms with society through narrative identity" (p. 243) and suggests such "autobiographical projects", "situated performances" and projections of the "dialogical self" share six common principles.

We have allowed for an overlapping in framing four considerations-identity construction, memory, history, and imagination-within six principles. For this reason, our four considerations will be used as section headings. The principles are grouped under these headings. We also call your notice to the feature that McAdams' (2008) six principles are only listed as discrete entities for organizational purposes and our convenience. Once the sections are laid out, their vitality derives from their interaction and rearrangement.

\section{Section 1.1 Elements of Identity Construction in Life Stories}

McAdams' (2008) Principle 1: The Self Is Storied, conflates consciousness with the power of storytelling, in which one's "self is both the storyteller and the stories that are told" (p. 244) in strategic and selective ways that are "both the reconstructed past and the imagined future" (p. 244). This principle, as do all the other principles, interacts with one's memory, history, and imagination. It is cited here as one of the prime elements in identity construction as a way in which we conceptualize our self.

In W.E.B. Du Bois' (1989) Souls of Black Folk, the process of conceptualizing the self in reflection, as an act of identity construction, is one whereby the coming to consciousness of identity feels like the construction of one's surroundings when exactly the opposite is taking place. Du Bois (1989) writes of the self-knowledge of his character, John Jones (whose life story resembles Du Bois' in a semi-autobiographical fashion - for example, in the fact that "As a child, Du Bois attended the Congregational Church in Great Barrington, Massachusetts ... [and, later in Du Bois' life,] ... members collected donations to pay Du Bois's college tuition") $)^{3}$.

In Du Bois' (1989) section on John Jones, we read of Jones that,

The world toward which he strove was of his own building, and he built it slow and hard. As the light dawned lingeringly on his new creations, he sat rapt and silent before the vision, or wandered alone over the green campus peering through and beyond the world of men into a world of thought. (p. 10) 
We call attention to a further point where the reflection and self-knowledge is a sign pointing toward deeper understanding and a call to action. Du Bois (1989) writes that Jones had

left his queer thought-world and come back to a world of motion and of men. He looked now for the first time sharply about him, and wondered he had seen so little before. He grew slowly to feel almost for the first time the Veil that lay between him and the white world; he first noticed now the oppression that had not seemed oppression before, differences that erstwhile seemed natural, restraints and slights that in his boyhood days had gone unnoticed or been greeted with a laugh. (p.11).

Principle 2: Stories Integrate Lives, adduces the insight that one of the most important functions of stories is in providing a timeline against which the events in one's life may be sequenced and to which causality " - putting things together into a narrative pattern that affirms life meaning and purpose" (McAdams 2008, p. 245) - may be ascribed. We here observe that, of course, a timeline against which one recalls events - both recorded and reimagined - speaks to our sense of imagination and history. Here, it is the affirmation of meaning and purpose that makes this principle a prime element in identity construction.

\section{Section 1.2 Elements of Memory in Life Stories}

Principle 3: Stories Are Told In Social Relationships, highlights how life storytelling is a performative event in which the storyteller employs "master narrative positioning in storytelling" (McAdams 2008, p. 245) that is dramatic and entertaining and in which the teller is most effectively a heroic figure (a brave, courageous John Wayne type or a caring, concerned Florence Nightingale character). Here, we want to point out that the focus on where the storyteller is situated relative to other individuals in her or his social context alludes to the dialogic nature of life stories. We feel that memory as recollecting, recollecting as collecting again, and the memoirist as the judge and performer of what is selected for collection and display - as a curator and exhibitor of carefully chosen life artifacts - may be understood as a creative exercise in which the memoirist's recollection (which draws on imagination) has primacy (as a form of artistic license) over all other interpretations. McAdams' (2008) master narrative positioning term also triggers my thoughts on Mark Bracher's (1993) comments about master signifiers and secondary signifiers in Jacques Lacan's registers of subjectivity. Bracher (1993) comments that since our "identity is determined to a large degree by what happens to those signifiers that represent us - our master signifiers - particularly the alliances they form with and the wars they wage on other signifiers" (Bracher 1993, p. 25), we want them repeated often (p. 26). We feel that although master signifiers in Lacanian terms are entities like God, Government, Nature, and Law, with secondary signifiers acting as their supports (priests and piety, and police and lawfulness, for example, being secondary signifiers of God and Law), the nuance of master narrative positioning about one's life story is that one selectively remembers the events in which one exhibits traits associated with master signifiers and master narrators and that these create our sense of identity.

Speaking directly to the interplay of memory with identity construction, history, and imagination, Principle 4: Stories Change Over Time, considers the notorious instability of autobiographical memory as a feature rather than a contradiction in two senses. First, general aspects of past events are retained while people often misremember specific details. Second, new experiences that individuals have over time may be significant enough to form narrative identities. "As people's motivations, goals, personal concerns, and social positions change, ... their memories of important events in their lives and the meanings they attribute to these events may also change" (McAdams 2008, p. 246).

\section{Section 1.3 Elements of History in Life Stories}

We feel that Principle 5: Stories Are Cultural Texts, speaks to the historical and social justice function of life story records. McAdams (2008) observes that "life stories mirror the culture wherein the story is created and told" (McAdams 2008, 246) and describes how such stories "are born, they grow, they proliferate, and they eventually die according to the norms, rules, and traditions that prevail in a given society, according to a society's implicit understanding of what counts as a tellable life" (p. 246). We believe that the earlier consideration, that life stories mirror the culture wherein the story is created and told, suggests a further and social justice positioned orientation for this mirror. Namely, all life stories are mirrors we hold up to our own culture to investigate and interrogate whether 
there is a reflection of their truths in our present-day realities; we remark on how things have changed and how much effort remains to be made in redressing, in effectively redeeming, our individual life stories in cultural perspective, in seeing our personal life stories as involved in forming as well as responding to the social justice issues of our particular times. We critique our own society and personal conduct in reflection on earlier and other life stories.

On this last assertion, the critique of our society and personal conduct in light of our life stories from a social justice perspective, McAdams (2008) recounts Western versus Eastern differences in this regard.

European Americans may prioritize self-expressive functions, viewing personal narratives as vehicles for articulating the breadth, depth, and uniqueness of the inner self. By contrast, Chinese people may prioritize the self-directive function, viewing personal narratives as guides for good social conduct ... to understand one's appropriate position in the social world. (p. 247)

We feel that while the first blush in this generalization may contrast Western rugged individualism and emphasis on the uniqueness of one's voice and one's individual contribution versus Eastern social conscience, there is an additional gloss to be appreciated. Namely, conforming to "one's appropriate [we add this emphasis] position in the social world" serves to prohibit the sort of questioning of the legitimacy of the status quo that the Western perspective of individual self-determination accommodates. On the matter of the uniqueness of one's voice and one's contribution, one need not assume this must be at the expense of innovativeness and efficacy to promote positive collective longterm outcomes.

However, as McAdams (2008) notes, "power elites privilege certain life stories over others ... [and echoes a common understanding, with which we agree, that, ... it is painfully clear that life stories echo gender and class constructions in society and reflect, in one way or another, prevailing patterns of hegemony in the economic, political, and cultural contexts wherein human lives are situated" (p. 247). In terms of the challenge to "give voice to suppressed discourses and struggle to bring marginalized ways of imagining and telling to the cultural fore" (McAdams 2008, p. 247) in life stories, Larry Preston's (1995) "Voices from the Margins" describes how "theory more attentive to difference needs to gain access to the meanings that circulate within different lives, especially as reflected in literary writing of those who, themselves, speak and write from sites of difference" (p. 941).

Preston (1995) observes that the postmodern "view that language is central to how we understand ourselves and others is now rather unproblematic (Derrida 1982; KoJodny 1985; Miller 1988; Rorty 1989; Showalter 1982, 1985; Wittgenstein 1953; and countless others)[, that] ... 'empirical' patterns emerge because they reflect the ways in which linguistic meanings and practices have played out within the context of social life[, which lead to the conclusion that] ... it is no longer sensible to view different sociological 'ways of life' as anything more than the distinct meanings and practices - the language games - associated with different linguistic 'forms of life' " (Preston (1995), p. 943). I take the inference from this conclusion to be that the rules of this language game must expand to appreciate life stories as cultural texts.

\section{Section 1.4 Elements of History and Imagination in Life Stories}

McAdams' (2008) Principle 6: Some Stories Are Better Than Others, focuses on the moral dimension in life stories that goes beyond a recounting of personal history. Imagination — of envisioning a better life story for the future - may be used to guide personal transformation. We may see "psychotherapy as fundamentally a process of story reformulation and repair ... to transform ... faulty life narratives into new stories that affirm growth, health, and adaptation" (p. 248).

We will here touch the edges of psychotherapy to consider how, from a developmental standpoint, Mark Bracher (1993) notes, "the establishment of a cluster of master signifiers as the ego ideal, which originates in the child's attempt to be desired and loved" (p. 24) is intimately connected to the urge to have an identity in which one recognizes oneself and is recognized by others as a means to provide the feelings of coherence and continuity essential to identity. We interpret this to indicate that not only does identity intertwine memoir, but that imagining, inventing and innovating to produce a socially desirable outcome in one's life story is an ongoing process of creative engagement. McAdams (2008) writes, 
By the time children are able to generate their own accounts of personal memories, they also exhibit good understanding of the canonical features of stories themselves. Five-year-olds typically know that stories are set in a particular time and place and involve characters that act upon their desires and beliefs over time. (p. 251)

Children move to the concept of internalizing cultural norms and expectations about what should be in the "the story of an entire human life ... [and learn the conventions of] ... a cultural concept of biography" (p. 251), progress to linking narrative elements through a process of "causal coherence" (p. 252), and further imbue their life stories with "thematic coherence" (p. 252). McAdams (2008) concludes that "Once narrative identity enters the developmental scene, it remains a project to be worked on for much of the rest of the life course" (p. 252). I link history and imagination in this section because memoir uses imagination to create history.

In framing life's variations, as "narrating suffering, growth, and self-transformation" (McAdams 2008, p. 252), we agree that the concept of redemption is presented as the essential fabric of American life stories. We observe that we often offer ourselves comfort in the commonplace saying that everything happens for a reason, and we feel that what is missing in this bromide - that would give it significance in a dialogical sense - is that we make up the reason in a quest for redemption. McAdams (2008) says, "At the level of the life story, negative events seem to demand an explanation. They challenge the storyteller to make narrative sense of the bad thing that happened" (p. 253). We paraphrase McAdams (2008) in the assertion that life stories in the form of memoir and other autobiographical projects are "how [we] make sense of [our] lives in society and culture and how the stories [we] tell determine who [we] are and affect what we do" (McAdams 2008, p. 258). We substitute his pronouns "they" and "their" for "we" and "our" in this phrase.

We believe the gist of McAdams' (2008) "redemptive self" (p. 255) concept of one's life story is that positive meanings may be found in negative events. He reports consistent findings

that midlife American adults who score especially high on self-report measures of generativity-suggesting a strong commitment to promoting the well-being of future generations and improving the world in which they live (Erikson, 1963) - tend to see their own lives as narratives of redemption. (p. 255)

As a segue to the analysis of selected memoirists, the following three-sentence signpost summarizes where the journey along the principles of life stories has taken us in terms of identity construction, memory, history, and imagination: We may wish to say we are not what we were; rather, we are what we have become. Further explication is needed. Truly, we create ourselves based on what we wish to be; and what we wish to be derives from the redemption we seek, and in the context in which we seek it.

How redemption is sought in the context of personal memoir, and further insights this provides into the creative process, takes us to Part Two.

\section{Part Two: Analysis of Selected Memoirists}

Memoirists we will use span from memoir designed to be as accurate as journalistic reportage (George Orwell's 1980 Homage to Catalonia); include consideration of works that range from quasi-autobiographical embracing of one's sexuality, to challenging physical handicap, to declaredly factually inaccurate exploration of epilepsy and schizophrenia (Audre Lorde's 1982) "Biomythography" ZAMI: A New Spelling of My Name, Stephen Kuusisto's (1998) Planet of the Blind, and Lauren Slater's "Metaphorical Memoir" Lying); and then to a story written in personal narrative style, All Quiet on the Western Front: A Novel, so firmly reality based as to often be mistaken for a true story.

We will discuss this selection of memoirists from two perspectives - first, the interplay of identity construction, memory, history, and imagination will be examined; second, their techniques, their use of narrative structures and language to communicate their experiences and ideas will be analyzed - for insights into the creative process. This paper does not attempt to find every element in every example. Rather, the life stories presented are selected to engage with the theme of redemption and to allow for the exploration of the relationship between identity construction, 
memory, history, and imagination in memoir style life story works. Importantly, analysis of the craft and mechanics of writing and language will be presented to demonstrate how narrative structure, as well as the compelling experiences and ideas detailed in memoirs, may lead to an understanding of issues related to the creative process.

\section{Section 2.1 George Orwell's (1980) Homage to Catalonia}

Orwell (1980) went to Spain in 1936 to report on the Spanish Civil War as a journalist. He decided to become a participant and enlisted in the militia. Orwell's (1980) Homage to Catalonia begins with him joining the militia and ends with his return to England. We may consider Catalonia as three concentric circles of Orwell's (1980) personal narrative: i) his commitment to the battle for freedom, ii) his active participation in the cause, and iii) the events leading to his leaving Spain and returning to England.

Orwell's (1980) actions as a human and a writer, his global perspective that leads him to take action in striving toward global equality in real and material terms, may be seen in his identification with a larger cause. In Lacanian terms, as interpreted by Mark Bracher (1993), we may regard Orwell's (1980) identification with the ideal of a classless society as a function of Orwell's (1980) acceptance of the classless society as a master signifier of social justice. The creation of a socially just society is a redemptive calling, consistent with Bracher's (1993) comments on identity formation that I introduced in Section 1.4 above. Here we expand those comments, observing that Bracher (1993) notes the urge that requires one to feel one must have an identity in which one recognizes oneself and is recognized by others results in "the establishment of a cluster of master signifiers as the ego ideal, which originates in the child's attempt to be desired and loved - that is, recognized (passive narcissistic desire) — by the Other" (Bracher 1993, 24). Bracher (1993) continues that master signifiers provide feelings of coherence and continuity essential to identity and "are, as Lacan puts it, what makes a discourse readable (XVII 218)" (Bracher 1993, 24). Below, Orwell (1980) reflects on his personal development in recording his experiences in Spain in Catalonia in 1938. We regard this, in Lacanian terms, as how Orwell (1989) matures into his identity as a writer, embracing his ego ideal; and feel his sense of identity from his 1938 memoir is what gives his writing its personal intensity in his 1945 novel Animal Farm and 1949 novel Nineteen Eighty-Four. For now, let's return to Spain.

Use of narrative structures to communicate his experiences and ideas-how Homage to Catalonia works and why it works, some of the techniques that Orwell (1980) employs to engage with his readers, choices he makes in telling his story and the effect these choices have on the entire work - will be analyzed for insights into the creative process.

In commenting on the spirit in which he enlisted in the militia, Orwell's (1980) writing employs a parallel structure of argumentation that is effective because it appears to be merely explanation rather than an attempt to convince the reader. The following passage demonstrates the simple elegance of this method.

Above all, there was a belief in the revolution and the future, a feeling of having suddenly emerged into an era of equality and freedom. Human beings were trying to behave as human beings and not as cogs in the capitalist machine. (Catalonia, 6)

Here, the linking of positive ideas - revolution with equality and the future with freedom - convey a hopeful impression. The reader may feel Orwell (1980) is being objectively descriptive, but the effect is to provide a definition of human being (and of being human) as a condition of equality and freedom and an indictment of capitalism as a mechanism of dehumanization that turns people into cogs in a machine. Orwell (1980) employs this techniqueseeming to provide explanation, but really presenting a persuasive position - effectively throughout the book. From the perspective of identity formation, there is a clear link between Orwell's (1980) social action and his humanity.

Orwell's (1980) frequent flashbacks, rather than troubling the narrative as distractions, serve to make his writing more accessible and make his points more convincing. By jumping out of his timeline and speaking directly to the reader, Orwell (1980) communicates a deeper engagement with his inner journey and the significance of his experience. He reflects, "When we went on leave I had been a hundred and fifteen days on the line, and at the time this period seemed to me to have been one of the most futile in my whole life" (p. 103) and he goes on to say "but from a personal point of view - from the point of view of my own personal development - those first three or four months that I spent on the line were less futile than I then thought. They formed a kind of interregnum in my life, quite different from anything 
that had gone before and perhaps from anything that is to come, and they taught me things that I could not have learned in any other way" (p. 103).

From a creative process perspective, recalling Mihaly Csikszentmihalyi's (1996) observations on how mastering one's craft is an essential element of the creative process (Csikszentmihalyi 1996, p. 329), in terms of mastery of language techniques, we will frequently analyze language use as an element of praxis in the creative process. In the above extract, for example, Orwell (1980) builds his argument using sentences split by commas, and a rhetorical style made friendly and more informal by the use of the em-dash, so the reader has manageable chunks of thought to digest easily.

Orwell (1980) uses a powerful metaphor to describe the terrible situation of armed skirmishes he found once he was back in Barcelona as "violent inertia, a nightmare of noise without movement" (p. 131). Ending the chapter in which he describes his personal experiences during the street battles, Orwell (1980) employs a repulsive metaphor. "It is a horrible thing to have to enter the into the details of inter-party polemics; it is like diving into a cesspool. But it is necessary to try and establish the truth, so far as it is possible. This squalid brawl in a distant city is more important than might appear at first sight" (p. 149). These metaphors establish both the situation in Barcelona and Orwell's (1980) role as a responsible journalist in reporting events as he observed them first-hand.

In contrast to the succinctness with which Orwell (1980) frames political questions, his description of being shot through the neck presents minute details to evoke visceral responses by sharing Orwell's (1980) inner conversation.

They had just got me on to the stretcher when my paralyzed right arm came to life and began hurting damnably. At the time, I imagined that I must have broken it in falling; but the pain reassured me, for I know that your sensations do not become more acute when you are dying. I began to feel more normal and to be sorry for the four poor devils who were sweating and slithering with the stretcher on their shoulders. ... I knew what a sweat it was, having helped to carry a wounded man down a day or two earlier. The leaves of the silver poplar which, in places, fringed our trenches brushed against my face; I thought what a good thing it was to be alive in a world where silver poplars grow. But all the while the pain in my arm was diabolical, making me swear and then try not to swear, because every time I breathed too hard the blood bubbled out of my mouth. (p. 187)

Here Orwell's (1980) ability to describe his near-fatal wounding, to demonstrate his caring for his peers struggling to carry him, to reveal the reassuring discomfort of his returning sensations after being shot, and his grateful marveling at being in the world all serve to build a connection between the writer and the reader. Writers create relationships with their readers and in the above extract we see how skillfully Orwell (1980) opens himself to that relationship. Orwell's (1980) mortality, empathy, humanity, and humility are all offered up to his readers. As in other extracts, this demonstrates how memoir may blend compelling experience with creative technique.

Orwell's (1980) final paragraph, describing his journey home, uses a conversational tone and a travelogue style of writing that seem to balance charmingly nostalgic images with an ending that is a threatening premonition of World War II (and almost a Nostradamus-like prediction of the worldwide terrorist bombings we hear of on a near-weekly basis in 2017).

And then England-southern England, probably the sleekest landscape in the world. It is difficult when you pass that way, especially when you are peacefully recovering from sea-sickness with the plush cushions of a boat-train carriage under your bum, to believe that anything is really happening anywhere. Earthquakes in Japan, famines in China, revolutions in Mexico? Don't worry, the milk will be on the doorstep tomorrow morning, the New Statesman will come out on Friday. The industrial towns were far away, a smudge of smoke and misery hidden by the curve of the earth's surface. Down here it was still the England I had known in my childhood: the railway-cuttings smothered in wild flowers, the deep meadows where the great shining horses browse and meditate, the slow-moving streams bordered by willows, the green bosoms of the elms, the larkspurs in the cottage gardens; and then the huge peaceful wilderness of outer London, the barges on the miry river, the familiar streets, the posters telling of cricket matches and Royal weddings, the men in bowler hats, the pigeons in Trafalgar Square, the red buses, the blue policemen-all sleeping the deep, deep sleep 
of England, from which I sometimes fear that we shall never wake till we are jerked out of it by the roar of bombs. (p. 232)

Narrative structure and expert linguistic techniques may be identified in this paragraph. Orwell (1980) changes to the second person voice to speak directly to the reader. Similarly, the use of metaphor engages the reader by using familiar images to make the scene or condition the writer describes into a situation the reader already understands. Sea-sickness may be a metaphor for upsetting events such as those Orwell (1980) endured in Spain. Present comfort may be represented as the "plush cushions" one places between oneself and unpleasant realities. The passage, "Earthquakes in Japan, famines in China, revolutions in Mexico? Don't worry, the milk will be on the doorstep tomorrow morning, the New Statesman will come out on Friday" cautions against the world-weariness of feeling that calamities elsewhere are irrelevant as long as one's own comfort is assured and that the media will save us the trouble of thinking critically about what's happening in the world by interpreting it for us. Orwell's (1980) comment that "The industrial towns were far away, a smudge of smoke and misery hidden by the curve of the earth's surface" further evokes the sense that just as we believe the commonplace that time cures all sorrows, there's an equal temptation to feel that distance hides injustice. As a whole, this paragraph is used to summarize Orwell's contention that one (his readers) must always look below the surface to judge the facts while also paying close attention to how the "facts" were found and whose interests these "facts" actually serve.

Finally, we see the power of a single story in which the writer, George Orwell (1980), makes his case for his interpretation of events based primarily on what he witnessed with his own eyes and from the first-hand reports of trusted sources - friends he had served with in the militia - and this adds to the credibility of his writing to support his goal of getting the actual fact situation - in contradiction of the popular press's version - presented for public knowledge. This knowledge also plays an important role in change even if that change is only a change in attitude because, on a larger scale, a change in attitude may amount to a shift in public opinion. Moreover, a shift in public opinion may fuel the desire and demand for greater equality; and what may seem like a vague notion-freedom and equality - has the power to mobilize tens of thousands of people to commit their lives and risk losing their lives to struggle for a better world. This sentiment echoes Orwell's (1980) original comments that link revolution and the future with equality and freedom.

Ultimately, there is a question of how the title contains the work. In Homage to Catalonia, the word homage may be read as a double-entendre. Homage is, of course, meant to be respect and reverence. It has also come to be a way to describe the attempt to capture an essence one might aspire to while appreciating one may never achieve, as when popular (at this writing) pop icon Katy Perry performs in costumes and styles described as homages to 1940's pin-up model Betty Grable. Just as Grable's influence endures (and the word "endures" also admits double-entendre), Orwell's (1980) commitment to the essences of equality and freedom - in his actions and in his writings - continues to be inspirational. His memoir continues to be inspirational for its content and for the insights into the creative process to be gained through reflecting on his command of his craft.

\section{Section 2.2 Audre Lorde's (1982) Zami}

In Audre Lorde's (1982) Zami, we see the transformational nature of honest truths that are shared in a personal story. As Lorde (1982) writes about her childhood and upbringing, there is also the presence of other opinions and the context of historical events as a background to the action in her life. We further appreciate that the background doesn't just exist like wallpaper in a room; the context forms her identity.

In Zami, there are six interactions taking place in terms of identity. The first two, noted above, are that the reader sees how Lorde's (1982) identity is formed in her household, with historical events in the background and also how the historical events shaped and formed her identity. We realize this context would have also had an effect on othersthat her writing could speak for a generation. There is some additional delight that, paradoxically, Lorde's (1982) quest to be so unique and individual, illustrated wonderfully in her "Being together was not enough. We were different" (Lorde 1982, p. 226) mantra, is what allows the reader to identify with her-to consider how much the common ground we have with others is so often so clearly displayed when we are attempting to assert our own claims of distinctiveness. As is human, we naturally reference Lorde's (1982) experiences growing up in terms of our own experiences, thinking about our personal identity and posing the question, "What made me what I am and what is it 
that I am anyway?" Then we must recall Lorde (1982) says her memoir is a "biomythography" and question which parts were rearranged, embellished, compressed, edited in or out to tell the story more captivatingly and to make her points more persuasively. Which parts of Lorde's (1982) identity were formed as she describes and which parts were constructed/ developed in the process of her telling her story? This understanding also serves as an incentive to reflect on our particular and individual stories.

Now, moving from what memoir does to reveal identity, to how it practices the craft of writing, takes us from content to technique and into the exploration of the relationship between these aspects of memoir. In particular, the idea of personal stories as drawing in voices from the fringe echoes Larry Preston's (1995) earlier comments on voices from the margins and Nussbaum (1995) and Rorty's (1998) assertions ${ }^{4}$ on the work that personal stories do in understanding other communities and in creating more humane social contexts.

In writing about her identity, Lorde (1982) gently invites readers to engage with looking at the world from an outsider's perspective, from a fringe position. "I have often wondered why the farthest-out position always feels so right to me; why extremes, although difficult and sometimes painful to maintain, are always more comfortable than one plan running straight down a line in the unruffled middle" (p. 15). Lorde's (1982) query brings to mind travel writer Pico Iyer's (2014) reason for moving to Kyoto. He says that "the margins are where the deepest interest lies. The nape of a neck, the gold embroidery along a kimono's edge, barely visible... it's in the empty spaces of a local painting, the white space around a haiku, that all the power lies".

The next passage from Zami is about Lorde's (1982) childhood. "All our storybooks were about people who were very different from us. They were blond and white and lived in houses with trees around and had dogs named Spot. I didn't know people like that anymore than I knew people like Cinderella who lived in castles. Nobody wrote stories about us" (p. 18).

Confronting racism and her otherness, Lorde (1982) writes, "The waitress was white, and the counter was white, and the ice cream I never ate in Washington, D. C. that summer I left childhood was white, and the white heat and the white pavement and the white stone monuments of my first Washington summer made me sick to my stomach for the whole rest of that trip and it wasn't much of a graduation present after all” (p. 71).

A sense of place and identity is formed in attentiveness to the fringes. It is formed by our responses to information in front of us, like the storybooks in which there is no part for Lorde (1982). Identity is also formed by the responsesboth personal and institutional - that others have to us, as in the case of the waitress and the racist segregation laws. Lorde (1982) saw herself, and we experience her feeling of that perception, as an individual on the fringes of whiteness. From the content in the description and the stylistic repetition of "white" five times in a single sentence, to the gutwrenching effect it has on Lorde (1982) as a little girl, Lorde's (1982) memoir engages us with the experience of being marginalized.

In the epilogue to ZAMI: A New Spelling of My Name, Lorde (1982) explains the meaning of the title and we appreciate that it is linked to her redemption as an acknowledgement of herself and as her connection to her community. "Zami. A Carriacou name for women who work together as friends and lovers" (p. 255).

\section{Section 2.3 Stephen Kuusisto's (1998) Planet of the Blind}

In a work in which the memoirist is redeemed from bitterness with his life, in reflecting on how the sense of redemption is woven into memoir, Stephen Kuusisto's (1998) Planet of the Blind presents his coming to terms with blindness by growing into the "master narrative positioning in storytelling" (McAdams 2008, p. 245). Kuusisto's (1998) transformation is dramatic and entertaining as he moves from an attitude of shame and denial (riding a bicycle pretending he can see in a desperate attempt to disguise his blindness) to the acceptance of his limitations leading to successes as a result of his courage and determination.

Kuusisto's (1998) memoir, from a creative process perspective, is a wonderful study in the technique of writing from scene to scene to scene, as creative nonfiction authority Lee Gutkind (2012, p. 105) advises. It also presents an interesting perspective on how identity forms on the fringes. The message of identity formation I take from Kuusisto's 
(1998) Planet of the Blind is that to grasp something, to create and understand one's identity, one must come to grips with what encloses it. In grappling to achieve a sense of self, to create a persona as an eleventh-grader, Kuusisto (1998) says, "I'm trying to turn cards over inside my head, but I can't get my fingers around their edges" (Kuusisto (1998), p. 61). Writing memoir becomes a way to grasp his identity as a man who is blind and who must create a way to interact with the world; "exploring what words can do when placed side by side, I'm starting to build the instrument that will turn my blindness into a manner of seeing" (p. 66). The challenge of blindness that Kuusisto (1998) responds to involves his growth and progress. He can, as McAdams (2008) says of the redemptive self, "make a happy ending, even in a threatening world."

\section{Section 2.4 Lauren Slater's (2000) Lying: A Metaphorical Memoir}

In terms of what has the design of a personal narrative and is only possibly true, we may reflect on Lauren Slater's (2000) Lying: A Metaphorical Memoir. Lying seems to represent the farthest fringe of the memoir as the complete creation of the self with the declaration that a fictitious self may be being created. Lying also lays down a dare in experimenting with whether simply using the word memoir, notwithstanding the fact that "lying" and "metaphorical" also appear in the title, creates the expectation and demand that everything contained therein must be factually true.

While McAdams (2008) references the notorious instability of autobiographical memory in Principle 4, that Stories Change Over Time, Slater (2000) utilizes that instability as a force in her creative process. In Lying, Slater (2000) constantly challenges the need for the sort of factual accuracy Lee Gutkind (2012) demands. She alerts us that her writing comes from "my emotional memory, which is not the same as my factual memory" (Slater 2000, p. 127) and digs deeply through the layers of identity. Challenging the notion of who one's true self is, Slater (2000) says "he slept not with Lauren Jean but with his idea of her talent, which was, I now see, an idea overwrought and ridiculous and possibly even entirely fraudulent, even though, dear reader, well, I do have some talent, wouldn't you say? I put myself in your hands. In his hands. We went back to his room" (p. 138). Slater (2000) explores the notion that with memory "a door opens, and through it pours the past ... [presenting the case that] ... some neurologists say that the memories are meaningless and not even accurate, random spurts from a hyperactive brain; others say the scenes that rush up are loaded with deep clues as to who and what we are" (p. 144). The tantalizing question is in how the past that pours through the door has been constructed. Slater (2000) proclaims she has, in a consciously envisioned creative process, employed the effects of social expectation, personal and cultural history, and imagination to reimagine and reformulate her declaredly non-memoir memoir. Finally, Slater (2000) presents the idea of identity as 'you are who you think you are' and sets forth the opinion that agreement about what is true is always a matter of interpretation. "And anyway, just because something has the feel of truth doesn't mean it fits the facts. Sometimes, I don't even know why the facts should matter. I often disregard them, and even when I mean to get them right, I don't' (p. 145).

Gutkind (2012) pronounces, "The cardinal rule is clear - and cannot be violated. This is the pledge the writer makes to the reader - the maxim we live by, the anchor of creative nonfiction: "You can't make this stuff up!" (Gutkind 2012, 7). He also adds considerations that modify the cardinality: "You must attempt to achieve a chain of truths: be true to your story, true to your characters, true to yourself" (p. 29). "You have your incident or situation. Now make it mean something bigger" (p. 30). "Objectivity is impossible unless, perhaps, you're a robot" (p. 34). Slater's memoir's "feel of truth that doesn't fit the facts" certainly privileges process over product, preferring "feel" to Gutkind's (2012) anchor and chain dictum.

Slater (2000) declares her honest beliefs tentatively, with circumspection about what happened and almost apologetically. This is a disarming quality that moves the reader, despite cautions to the contrary, to want to trust Slater's (2000) story. Her challenge to the requirement for veracity in memoir also leads us, now, to examine an opposite approach; it's one that's grounded in factual accuracy. Historical fiction proceeds with exact certainty. Its details are verifiable. However, from a first-person perspective in memoir style, it also reveals elements of identity formation, the quest for redemption, and the workings of the creative process. 


\section{Section 2.5 Erich Maria Remarque's (2013) All Quiet on the Western Front: A Novel}

Here, we move to All Quiet on the Western Front: A Novel, as a work written in personal narrative style that Erich Maria Remarque (2013) fictionalized from elements of his own life story. "In the course of just a few months in 1927, drawing on his brief experience of combat as a teenage German conscript and the year-plus he spent in a military hospital recovering from shrapnel wounds, he set down in plain terms the story of a fictional everyman, young Private Paul Baumer. It became an account, presented in raw and visceral terms, of how the war destroyed Baumer spiritually, stripping him of all hope of a future before finally, perhaps mercifully, taking his life" (Meyer, Loc. 2813).

Erich Maria Remarque's (2013) All Quiet on the Western Front conveys a life story in the context of a work of fiction from the viewpoint of a young German soldier serving during World War I. Through compelling personal narrative and a variety of ways with language - concentration, close description, rhythm, metaphor, poetic sensibilityRemarque (2013) has combined identity construction, memory, history, and imagination.

In greatest part, analysis of Remarque's (2013) language techniques will be used as the entry point to the creative process. This approach begins with a defining moment in the narrative. The event takes place when all the men are issued new uniforms, better food is provided, and commanders busy themselves overseeing refurbishing everything at the position where the protagonist is posted. At first the men imagine the war has ended and this has resulted in such sudden abundance. To their vexation, they quickly learn the real reason for this transient plenty is that the Kaiser will be inspecting the front lines.

At last the moment arrives. We stand to attention and the Kaiser appears. We are curious to see what he looks like. He stalks along the line, and I am really rather disappointed; judging from his pictures I imagined him to be bigger and more powerfully built, and above all to have a thundering voice. He distributes Iron Crosses, speaks to this man and that. Then we march off. Afterwards we discuss it. Tjaden says with astonishment: 'So that is the All-Highest! And everyone, bar nobody, has to stand up stiff in front of him!' (p. 202 | Location 1925-29)

Communicated in personal narrative style, we feel the sheer banality of political power mixed with anticlimax on the part of the rank-and-file soldiers. The rhythm of this paragraph telegraphs the mechanical nature of the experience. The first three sentences are as unremarkable as the Kaiser turns out to be. A mechanical going-through-the-motions impression is conveyed in the short, abrupt sentences - both their diction and syntax - used to report the event. The visit is chronicled using subject-verb phrases that communicate only the regimented artificiality of the experience"the moment arrives, we stand, we are curious, he stalks, he distributes, we march off"-with virtually no description.

The only elements of authenticity and vitality are in Remarque's (2013) character's mind - "I imagined him to be bigger and more powerfully built, and above all to have a thundering voice"-and in the lively conversation of the other soldiers, who share the central character's sentiments, after the event. In their pre-battle reveries - their life story formulations - young soldiers may have yearned to imagine facing death in the service of a larger and more formidable truth, "bigger and more powerfully built"; that is supremely authoritative "above all to have a thundering voice"only to be astonished at their naivety. Juxtaposition of the elements operating in the paragraph contributes to the soldiers' sense of helplessness. They don't reach the moment; the moment "arrives". It controls their lives. They must "stand to attention", contrite and regimented while grounded to the earth. The Kaiser "appears" the way an apparition might materialize. The soldiers express human curiosity; the Kaiser "stalks" like a predator.

Word choice, punctuation and direct quotation in the extract- "Afterwards we discuss it. Tjaden says with astonishment: 'So that is the All-Highest! And everyone, bar nobody, has to stand up stiff in front of him!' "-ends this passage with political commentary that directly challenges the status quo. "Afterwards we discuss it", in describing conversation among equals, evokes an ideal of equality. Colons precede proof or demonstration and, in this extract the syntactical-deductive colon introduces the logical consequence of an earlier condition (the challenge to the requirement "to stand up stiff in front of" the Kaiser) for discussion. The use of the stative adjective, "astonishment" in describing Tjaden's condition (and exclamation marks in each of Tjaden's statements) challenges obedience to political privilege and authority. 
The central superficiality of the moment is striking. The Kaiser arrives and leaves, and nothing has changed. On reflection, we see that this scene reveals the storyteller's helplessness. Imagining his vulnerability as our own evokes the realization that only protocol makes the distinction between the Kaiser's fate and that of the soldiers; the soldiers follow it and die for it. The power an individual's experience conveyed in memoir style, even if employed in historical fiction, imbues All Quiet on the Western Front's readers with a sense of frustration and anger at the waste of war.

Returning to Gutkind's (2012) guidance on the creative process of moving from scene to scene to scene and how each scene must be written to have the intensity to stand alone, Remarque has created a scene filled with tension and expectation. There is the possibility of confrontation between ordinary soldiers and the cause of their and Germany's misery. Yet, it's clear this won't happen. The brief, formal and hollow experience of standing at attention while the Kaiser stalks past creates a feeling of juxtaposition and of irony. The soldiers' perfunctory presence contrasts with the Kaiser's presence. He is the Emperor, symbolizing absolute authority and whose "open enjoyment of the title of Supreme War Lord" "was well known; they are symbols of powerlessness and hopelessness.

Other examples, which circle outward from this scene, will be briefly referenced to consider some of the uses of language Remarque calls into service to instill All Quiet on the Western Front with the lifeblood of memoir-its severe immediacy. On this point, we suggest the distinction between personal narrative style and philosophical reflection in relation to the idea of proximity. Namely, that philosophical reflection is a process of stepping back and attempting to adopt an objective stance while personal narrative style is so subjectively proximate that it requires the reader to engage with the storyteller's identity and redemptive quest.

In the case of All Quiet on the Western Front, the proximity of Remarque's (2013) character to the experience of war sustains the tone of personal narrative. Whether Remarque (2013) is presenting chilling metaphors in the midst of the experience - "deadly tension that scrapes along one's spine like a gapped knife" (p. 111|1079-80) — or sharing ghastly details of the battlefield ${ }^{8}$ (p. $134 \mid 1297-1303$ ), exquisitely beautiful descriptions of light through forest trees ${ }^{9}$ p. (188 | 1802-7), or contemplations on the fraternity of humanity that even killing another human cannot extinguish ${ }^{10}$ (p. 223 |2135-39), the confidential tone and stark intimacy of personal narrative is operative.

Remarque's (2013) use of the memoir style in his creative process brings to my mind John Dewey's (1934) remark that "the characteristic of artistic design is the intimacy of the relations that hold the parts together" (Dewey 1934, p. 121). Now, in drawing this exploration of the creative process in memoir (with the element of redemption as a recurring motif) toward its conclusion, we will consider what holds its parts together.

\section{CONCLUSIONS AND REFLECTIONS ON THE CREATIVE PROCESS, MEMOIR, AND REDEMPTION}

We will not try to draw great and lofty conclusions; instead, some modest connections will be suggested.

Following on from the application of John Dewey's (1934) comment to Remarque's creative process, we chime in with two additional associations from Art as Experience.

On the reinvention of the self as a process of experience from which selected memories and imagination recombine, resonating with Audre Lorde's (1982) Zami and Lauren Slater's (2000) Lying, Dewey's (1934) observation that "whenever anything is undergone in consequence of a doing, the self is modified" (p. 10) resounds.

On the matter of evolving in time, of memoir providing a timeline against which the events in one's life may be sequenced, characterized in Dewey's (1934) comment that "the real work of an artist is to build up an experience that is coherent in perception while moving with constant change in its development" (p. 53), George Orwell's (1980) memoir of his military service in Spain and near-death (in both senses of that phrase) experience, Homage to Catalonia, and Stephen Kuusisto's (1998) transition through Planet of the Blind reverberate.

Each of the above memoirs contains a redemptive message.

The last literary reference we will make is to Frankenstein, which, like All Quiet on the Western Front, is not a memoir. Yet, like All Quiet on the Western Front, Frankenstein is written in memoir style. Unlike stories of the redemptive 
self, Frankenstein and All Quiet on the Western Front have no happy endings; they end in death. However, very much like stories of the redemptive self, there is a generative message "my death shall not have been in vain if it serves as a warning (of science of hubris rather than humility and conscience (Frankenstein) or of the futility of war (All Quiet on the Western Front)" that mirrors the generative sentiment that "my life shall have had purpose in making the world a better place for future generations."

In the final scene of Frankenstein, the nameless hideous being anguishes over his creator's corpse. The monster laments, "When I run over the frightful catalogue of my sins, I cannot believe that I am the same creature whose thoughts were once filled with sublime and transcendent visions of the beauty and the majesty of goodness" (Shelley (1998), Loc. 2882-84). The message that nothing could be worse than having no hope for redemption is contained in the nuance - as the creature is "borne away by the waves and lost in darkness and distance" (Loc. 2914) - that he is moved to self-immolation not by remorse but by his being forever barred from redemption. In this way, in a demarcation between human and non-human, the creature is also barred from what we may all legitimately seek and what makes us human.

On the connection between having a social and cultural memoir-the sort of authentic life story that the monster does not have-McAdams (2008) concludes that "life stories make up a domain of personality structure and functioning that is separate from, though related to, the well-established domains of dispositional traits and characteristic adaptations" (McAdams (2008), p.257).

We feel that it is in this third domain that the redemptive self-resides and that this absence, expertly rendered in Shelley's (1998) monster, is what denies him any hope for redemption. That's the connection. ${ }^{11}$ As a final coda to the question of life stories and the quest for redemption, Martin E.P. Seligman and John Tierney (2017) provide insight from the field of prospective psychology. Prospecting to create a better future, they write, is the chief feature that makes us human. "The brain's long-term memory has often been compared to an archive, but that's not its primary purpose. Instead of faithfully recording the past, it keeps rewriting history." ${ }^{\prime 2}$ We see this as a process of seeking redemption in the narratives we create and stories we tell.

In closing, we trust this paper has served to demonstrate how narrative structure, as well as the compelling experiences and ideas detailed in memoirs, may lead to an understanding of issues related to the creative process.

\section{AUTHOR BIOGRAPHIES}

Lawrence Karn, Ph.D. is Specially Assigned Lecturer of English at Otsuma Women's University, Japan; Adjunct Professor at Tokyo University of Foreign Studies, Japan, and at the Jikei Medical University in Tokyo. Dr. Karn is the Vice-chairperson of the Advisory Committee for the United Nations Association's Test of English. Email:karn@unaj.or.jp

Takahiko Hattori, Ph.D. is Professor of Linguistics and Language Research at Otsuma Women's University, Japan and a Lecturer at Waseda University, Japan. He has published extensively, and made presentations both in Japan and North America related to English Language Education. He is the Executive Supervisor for the United Nations Association's Test of English. E-mail: hattori@otsuma.ac.jp

This paper was written in the main by Lawrence Karn, with the very kind assistance and support of Takahiko Hattori. 


\section{REFERENCES}

Aristotle (1961). Poetics. Trans. S.H. Butcher. New York: Hill and Wang, [Kindle Edition, Nov. 3, 2008 release date.] Rhetoric. Trans. W. Rhys Roberts. http://www.bocc.ubi.pt/pag/Aristotle-rhetoric.pdf

Bracher, M. (1993). Lacan, discourse, and social change: A psychoanalytic cultural criticism. Cornell UP.

Csikszentmihalyi, M. (1996). Creativity: Flow and the psychology of discovery and invention. New York: HarperCollins. Dewey, J. (1934). Art as Experience. New York: Perigee Books, 3-19. 344-49.

Du Bois, W. E. B. (1989). The souls of black folk. New York: Penguin Books, [1903], chapters 1, 1-12; 13, 186-203.

Du Bois, W. E. B. https://en.wikipedia.org/wiki/W._E._B._Du_Bois\#cite_note-1

Gutkind, L. (2012). You can't make this stuff up: The complete guide to writing creative nonfiction from memoir to literary journalism and everything in between. Philadelphia: Da Capo Press/Lifelong Books.

Iyer, P. http://www.bbc.com/travel/feature/20140716-the-walk-that-made-me-love-japan

Kaiser Wilhelm II. http://www.history.com/topics/world-war-i/kaiser-wilhelm-ii

Kuusisto, Stephen. (1998). Planet of the blind. New York: Delta Trade Paperbacks.

Lorde, A. (1982). ZAMI: A new spelling of my name. Freedom: The Crossing Press.

McAdams, D. P. (2008). "Personal narratives and the life story" in John, O., Robins, R., \& Pervin, L. A., Handbook of personality: Theory and research (pp. 241-261). Guilford Press. This article is at http://www.redemptiveself.northwestern.edu/docs/publications/1698511162490a0d856d825.pdf “American Identity: The Redemptive Self" at http://www.redemptiveself.northwestern.edu/docs/publications/2094657112490a0f25ec2b9.pdf, page 20. http://www.redemptiveself.northwestern.edu

Meyer, G. J. "The Enduring Impact of All Quiet on the Western Front" essay afterward to All Quiet on the Western Front: A Novel. Kindle Edition.

Nussbaum, M. C. (1995). Poetic justice: The literary imagination and public life. Boston, MA: Beacon Press.

Orwell, G. (1980). Homage to Catalonia, Harcourt Inc.

Preston, L. (Dec. 1995). Theorizing difference: Voices from the margins. American Political Science Review, 89(4), 941-953.

Remarque, E. M. (2013). All quiet on the western front: A Novel. (1928). Random House Trade Paperbacks Random House Publishing Group. Kindle Edition.

Rorty, R. (1989). Contingency, irony, and solidarity. New York: Cambridge University Press. "Human Rights, Rationality, and Sentimentality." Truth and Progress: Philosophical Papers, 3. New York: Cambridge Press, 1998.

Seligman, M. E. P. and Tierney, J. (1998). We aren't built to live in the moment. The New York Times. https://www.nytimes.com/2017/05/19/opinion/sunday/why-the-future-is-always-on-yourmind.html?action=click\&pgtype $=$ Homepage \&clickSource= $=$ story-heading \&module=opinion-c-col-rightregion\&region=opinion-c-col-right-region\&WT.nav=opinion-c-col-right-region, 5 May 2017.

Shelley, M. W. Frankenstein, or, the Modern Prometheus. 1831 ed. New York: Dover. Project Gutenberg Kindle Edition. Slater, L. (2000). Lying. New York: Penguin Books. 


\section{ENDNOTES}

${ }_{1}^{1}$ McAdams, Dan P. http://www.redemptiveself.northwestern.edu/docs/publications/2094657112490a0f25ec2b9.pdf, page 20.

${ }^{2}$ McAdams cites a number of contact points that interact with daily life activities as well as the wider range of designations, (figure 8.1 on 249 includes Human Nature, Culture, Dispositional Traits, and Characteristic Adaptations), to suggest narrative identity is a social construct. http://www.redemptiveself.northwestern.edu/docs/publications/1698511162490a0d856d825.pdf

${ }^{3}$ https://en.wikipedia.org/wiki/W._E._B._Du_Bois\#cite_note-1

${ }^{4}$ As a subheading that would be titled "worthy sidebars" to the discussion in Section 2.2 above, the idea of personal stories drawing in voices from the fringe, that echoes Larry Preston's (1995) comments on voices from the margins, also bears on Martha Nussbaum and Richard Rorty's assertions on the work personal stories do in understanding other communities and in creating more humane social contexts.

While not specifically referring to (or excluding) memoir, Nussbaum (1995) chooses novels, in particular, as important creative works in terms of "literary imagination and public life" because they invoke a story arc that confer the "ability to imagine what it is like to live the life of another person who might, given changes in circumstances, be oneself or one of one's loved ones" (Nussbaum (1995), 5).

This is a sentiment Rorty (1989) also expresses. He refers to this action as "sentimentality" and describes how it operates through sharing of stories that touch our similarities. He suggests the sorts of long sad stories that put us in another person's position are the ways to invoke a more useful sense of culture. Rorty's (1989) relevant question isn't “ 'Why should I be moral?' but rather ... 'Why should I care about a stranger, a person who is no kin to me, a person whose habits I find disgusting?' [and advises that a] ... better sort of answer is the sort of long, sad, sentimental story that begins, "Because this is what it is like to be in her situation" (Rorty (1989), "Human Rights, Rationality, and Sentimentality", 185). In terms of the socially transformative potential of Rorty's (1989) invocation to experience the lived reality of the other, his observations on changing the vocabulary/ the narrative itself by understanding, reinvention and refusing to "play by the rules of somebody else's final vocabulary" (Contingency, Irony, and Solidarity, 133) are part of the action plan.

Nussbaum (1995) and Rorty (1989) are clearly on the same page, with an "interest in the ordinary" (Nussbaum (1995), 9) and in Rorty's (1989) comment above ("Human Rights, Rationality, and Sentimentality", 185) even though they pen different marginal notations on that page. Nussbaum (1995) argues for the novel as the best way to "get potentially universalizable concrete prescriptions by bringing a general idea of human flourishing to bear on a concrete situation, which we are invited to enter through the imagination" (8). Rorty (1989) would abjure the universalizable concrete prescriptions part of Nussbaum's (1995) sentiment while expanding the texts from novels to a wider range of literature, including oral traditions and spoken word testimonies. While Nussbaum advises that literary "insights should not displace the workings of economic science" (12), Rorty (1989) would challenge economic science to present the sort of insights into the human condition a literary imagination provides.

While neither Nussbaum (1995) nor Rorty (1989) explicitly discuss the role of memoir, which is why these observations appear in these notes rather than in the body of the paper above, we nevertheless contend they apply to memoir.

${ }_{6}^{5}$ Iyer, Pico (2014). http://www.bbc.com/travel/feature/20140716-the-walk-that-made-me-love-japan

${ }^{6}$ McAdams, Dan P. (2014) http://www.redemptiveself.northwestern.edu/docs/publications/2094657112490a0f25ec 2b9.pdf, page 20.

${ }^{7} \mathrm{http}: / /$ www.history.com/topics/world-war-i/kaiser-wilhelm-ii

8 "We see men living with their skulls blown open; we see soldiers run with their two feet cut off, they stagger on their splintered stumps into the next shell-hole; a lance-corporal crawls a mile and a half on his hands dragging his smashed knee after him; another goes to the dressing station and over his clasped hands bulge his intestines; we see men without mouths, without jaws, without faces; we find one man who has held the artery of his arm in his teeth for two hours in order not to bleed to death. The sun goes down, night comes, the shells whine, life is at an end. Still the little piece of convulsed earth in which we lie is held. We have yielded no more than a few hundred yards of it as a prize to the enemy. But on every yard there lies a dead man" (All Quiet on the Western Front, 134 | Loc. 1297-1303).

9 "But the most beautiful are the woods with their line of birch trees. Their color changes with every minute. Now the stems gleam purest white, and between them airy and silken, hangs the pastel-green of the leaves; the next moment all changes to an opalescent blue, as the shivering breezes pass down from the heights and touch the green lightly away; and again in one place it deepens almost to black as a cloud passes over the sun. And this shadow moves like a ghost through the dim trunks and rides far out over the moor to the sky - then the birches stand out again like gay banners on white poles, with their red and gold patches of autumn-tinted leaves" (All Quiet, 188 | Loc. 1802-7).

10 "I speak to him and to say to him: 'Comrade, I did not want to kill you. If you jumped in here again, I would not do it, if you would be sensible too. But you were only an idea to me before, an abstraction that lived in my mind and called forth its appropriate response. It was that abstraction I stabbed. But now, for the first time, I see you are a man like me. I thought of your hand-grenades, of your bayonet, of your rifle; now I see your wife and your face and our fellowship. Forgive me, comrade" " (All Quiet, 223 | Loc. 2135-39).

${ }^{11}$ (This note, as a further connection, was to have been the second-last paragraph of the paper. It appears here because its considerations would have expanded the conclusion section beyond its proposed modest connections.)

This paper has sought to engage with the question of what memoir tells us about the creative process. This also poses the additional question, "What does the creative process tell us about how we recall our life stories?" It tells us memoir is not only a way, but may be the way we best understand our places in the world. We want life's meaning to be conveyed viscerally, emotionally, as a lived truth even if the teller didn't truly live it. In memoir and memoir-like first-person narratives the storyteller gives the story emotional life in the most elegant and powerful, tender and loving, passionate and compelling manner possible. Craving redemption, we implore the memoirist. Analytically, for more than profuse panegyric to memoir as a demonstration of the writer's craft, this essay's engagement with the creative process must also regard memoir as a style within the pantheon of writing genres. Moreover, respecting other forms in the acropolis of creative expression, the question of how memoir is representative of all of our creative processes - be they visual arts, dance, and myriad others - may be posed. For this entreaty, we invoke and end with rhetorical categories of the creative process Aristotle's Rhetoric provides, but extend them beyond oratory: An individual may implore, "Persuade me with the logical power of the story. Convince me with the charm and appeal of your character. Let me believe you are speaking directly to me about experiences vital to my life. Respect the logos of the event's significance, but also allow me to appreciate the ethos with which you tell the story-your life story as an entry point, as a dialogic invitation to see the world from your perspective because, as blinded Lear said to the fool, speak so that I may see you."

We ask memoirists to tell their stories so that we may know them, may be engulfed in their ethos and by their ethos; which is what happens in the best of memoirs. In satisfying our requests, the memoirist has cared for our feelings and our response — not as pandering, but as pathos. Memoir speaks to each person, from person to person, with care and concern for each person's personal cares and concerns. Each memoirist 
writes of themselves and their concerns, but these are letters addressed to others. The basis for this assertion about memoir and the life storiesof the whole as represented by the individual - is part of the discussion of the nomothetic search for general laws or traits in life stories, wherein we learn there are a great number of studies that have established such quantitative measurement techniques for coding these narratives (McAdams 2008, 256). There remains a commitment to the idiographic approach "wherein subtle and complex patterns of human individuality can be exposed" (256), and even "examinations of the single case have ... illustrated the sweep and power of narrative theories of personality" (257). Using these observations as the basis for the conclusion that each memoirist writes of themselves and their concerns, but these are letters addressed to others, the reason we may state is that life stories are psychosocial creations and it cannot be otherwise.

${ }^{12}$ Seligman, Martin E.P. and Tierney, John. "We Aren't Built to Live in the Moment," The New York Times, https://www.nytimes.com/2017/05/19/opinion/sunday/why-the-future-is-always-on-your-

mind.html?action=click\&pgtype $=$ Homepage\& clickSource=story-heading\&module=opinion-c-col-right-region\&region=opinion $-\mathrm{c}-$ col-rightregion\&WT.nav=opinion-c-col-right-region, 5 May 2017. 